\title{
Coccidian parasites in the endangered Forest Musk Deer (Moschus berezovskii) in China, with the description of six new species of Eimeria (Apicomplexa: Eimeriidae)
}

\author{
Yunyun Gao ${ }^{1,2}$, Donald W. Duszynski ${ }^{3}$, Fulin Yuan ${ }^{1,2}$, Defu $\mathrm{Hu}^{1,2}$, and Dong Zhang ${ }^{1,2, *}$ \\ ${ }^{1}$ Key Laboratory of Non-Invasive Research Technology for Endangered Species, School of Nature Conservation, \\ Beijing Forestry University, Beijing 10083, PR China \\ 2 Department of Zoology, School of Ecology and Nature Conservation, Beijing Forestry University, 35 Qinghua East Road, \\ Beijing 100083, China \\ ${ }^{3}$ Emeritus Professor of Biology, 76 Homesteads Rd., Placitas, NM 87043, USA
}

Received 2 July 2021, Accepted 29 September 2021, Published online 19 October 2021

\begin{abstract}
We examined 674 fresh fecal samples from forest musk deer (Moschus berezovskii Flerov) in Sichuan and Shaanxi Provinces, China, for coccidian oocysts and $65 \%$ were infected with Eimeria spp. Previously, only four Eimeria species were known from Moschus spp. Here we describe six new Eimeria species. Eimeria aquae n. sp., in $38 \%$ deer, has ovoidal oocysts, $32.0 \times 23.0 \mu \mathrm{m}$, micropyle $(\mathrm{M})$ and scattered polar granules (PGs) of various sizes are present, sometimes oocyst residuum (OR) is present; ovoidal sporocysts, $14.1 \times 7.5 \mu \mathrm{m}$, with Stieda body $(\mathrm{SB})$ and sporocyst residuum (SR). Eimeria dolichocystis n. sp., in $11 \%$ deer; cylindroidal oocysts, $36.6 \times 18.9$, with a M, 1 PG and OR; ovoidal sporocysts, $13.9 \times 7.7$, with SB and SR. Eimeria fengxianensis n. sp., in $7 \%$ deer; ovoidal oocysts, $36.3 \times 25.2$, a M and PGs present but OR absent; ovoidal sporocysts, $13.9 \times 7.3$, with SB and SR. Eimeria helini $\mathrm{n}$. sp. in 24\% deer; subspheroidal oocysts, $27.0 \times 24.1$, OR and PGs often present, but M absent; ovoidal sporocysts, $13.5 \times 7.7$, with SB and SR. Eimeria kaii n. sp. in $26 \%$ deer; ovoidal oocysts, $33.2 \times 20.7$, M and PGs present, but OR absent; ovoidal sporocysts, $14.4 \times 7.5$, with SB and SR. Eimeria oocylindrica $n$. sp., in $17 \%$ deer; cylindroidal oocysts, $36.0 \times 21.4$, M and 1-2 PGs present but OR absent; ovoidal sporocysts, $13.8 \times 7.7$, with SB and SR. Eimeria dujiangyanensis n. nom. is proposed to replace E. moschus Sha, Zhang, Cai, Wang \& Liu, 1994, a junior homonym of E. moschus Matschoulsky, 1947.
\end{abstract}

Key words: Coccidia, Eimeria, New species, Prevalence, Moschus berezovskii.

Résumé - Coccidies parasites du cerf porte-musc (Moschus berezovskii), une espèce en danger en Chine, avec la description de six nouvelles espèces d'Eimeria (Apicomplexa, Eimeriidae). Nous avons examiné 674 échantillons de matières fécales fraîches de cerf porte-musc (Moschus berezovskii Flerov) dans les provinces du Sichuan et du Shaanxi, en Chine, pour les oocystes de coccidies et $65 \%$ étaient infectés par Eimeria spp. Auparavant, seules quatre espèces d'Eimeria étaient connues chez Moschus spp. Nous décrivons ici six nouvelles espèces d'Eimeria. Eimeria aquae n. sp., chez $38 \%$ des cerfs, a des oocystes ovoïdes, 32,0 $\times 23,0 \mu \mathrm{m}$, micropyle (M) et granules polaires (PG) de différentes tailles présents, parfois des résidus d'oocystes (OR) présents; sporocystes ovoïdes, $14,1 \times 7,5 \mu \mathrm{m}$, avec corps de Stieda (SB) et résidu de sporocyste (SR). Eimeria dolichocystis n. sp., chez $11 \%$ des cerfs; oocystes cylindroïdes, 36,6 × 18,9, avec un M, 1 PG et OR; sporocystes ovoïdes, 13,9 × 7,7, avec SB et SR. Eimeria fengxianensis n. sp., chez $7 \%$ des cerfs; oocystes ovoïdes, 36,3 $\times 25,2$, M et PG présents mais OR absent; sporocystes ovoïdes, 13,9 × 7,3, avec SB et SR. Eimeria helini n. sp. chez $24 \%$ des cerfs; oocystes subsphéroïdaux, 27,0 × 24,1, OR et PG souvent présents, mais M absent; sporocystes ovoïdes, 13,5 × 7,7, avec SB et SR. Eimeria kaii n. sp. chez $26 \%$ des cerfs; oocystes ovoïdes, 33,2 × 20,7, M et PG présents, mais OR absent; sporocystes ovoïdes, 14,4 × 7,5, avec SB et SR. Eimeria oocylindrica n. sp., chez $17 \%$ des cerfs; oocystes cylindroïdes, 36,0 × 21,4, M et 1-2 PG présents mais OR absent; sporocystes ovoïdes, 13,8 $\times 7,7$, avec SB et SR. Eimeria dujiangyanensis n. nom. est proposé pour remplacer E. moschus Sha, Zhang, Cai, Wang \& Liu, 1994, homonyme junior de E. moschus Matschoulsky, 1947.

*Corresponding author: ernest8445@163.com; zhangdong_bjfu@bjfu.edu.cn 


\section{Introduction}

Moschus is the only genus in the family Moschidae, with seven extant species, which are all called musk deer $[6,16$, 21]. Although they resemble small deer, they are not true deer (Cervidae) because they lack the antlers and facial glands of deer and because they possess only one pair of teats, a gall bladder, a musk gland in males, and a pair of tusk-like teeth that cervids lack [20, 24]. These small deer live in hilly scrub and forested habitat in the mountains of Asia (notably the Himalayas). They are solitary, shy herbivores with well-defined territories and are either crepuscular or nocturnal. Small populations are spread through many Asian countries (Afghanistan, Bhutan, Burma, China, India, Korea, Mongolia, Nepal, Pakistan, Russia [southeastern Siberia], Tibet, and Vietnam) where most species and populations are either declining, endangered or threatened because of poaching for their musk glands (cosmetics, perfumes) and/or because of excessive hunting for illegal trade and habitat loss due to deforestation [1, 20, 24, 26].

Moschus berezovskii Flerov, 1929, the Chinese forest musk deer, is distributed mostly in China where it is classified as "Endangered" by the International Union for Conservation of Nature (IUCN). Unfortunately, its populations were declining rapidly due to exploitation and extensive habitat loss [18, $23,25]$ until a captive breeding program for $M$. berezovskii began in China in 1958 [7, 8, 20, 24] and from that effort, 13 M. berezovskii ( 8 females, 5 males) were reintroduced back into the wild in 2017 (https://www.sohu.com/a/153114346_ 157267).

Gastrointestinal parasitism by microbes, protists and helminths is common in these musk deer and may lead to $>30 \%$ mortality rates in captive musk deer $[7,8,13]$ which have seriously hampered their population expansion. Based on several surveys of gastrointestinal parasitism of forest musk deer, oocysts of Eimeria spp. were the dominant parasite group observed, with high prevalence, and obvious differences of parasite infection in both musk deer sex and age groups [2, 12, 14]. In the wild, forest musk deer are extremely cryptic, and detailed accounts for gastrointestinal parasites in all age groups under natural conditions are lacking. Thus, captive animals provide an excellent opportunity to study and understand the parasite communities of wildlife and, in our work, especially the Chinese musk deer on 13 captive breeding centers in China.

Here we summarized our current knowledge of the morphology and taxonomy on the Eimeria species reported to date from Moschus species, described six new Eimeria species, and corrected the nomenclature of a previously named species based on scientific priority. We also evaluated the differences of the various Eimeria species between adult and juvenile musk deer.

\section{Materials and methods}

\section{Ethics approval}

Our fecal sample collections in this study were done with the approval of the School of Ecology and Nature Conservation, Beijing Forestry University (EAWC_BJFU_2021008), under the guidelines of the Institution of Animal Care and the
Ethics Committee of Beijing Forestry University, and the help of local veterinarians.

\section{Host and location information}

From August to September 2020, fresh fecal samples were collected from 674 forest musk deer in 13 captive breeding centers of forest musk deer in Sichuan and Shaanxi Provinces; these centers include more than $80 \%$ of all captive centers in China. All breeding centers have similar breeding systems, with a male and four or five females kept in the same enclosure, and each individual with ear tagging in adult and collar in young, has an independent brick cell as described in $\mathrm{Hu}$ et al. [7]. The staff of the breeding centers clean each cell every day, thus allowing the collection of fresh feces from each musk deer. In addition, all centers are located in the mountains at an altitude of 1100-1500 m close to the Qinling Mountains and Tibetan Plateau, an area that is incredibly rich in biodiversity. Such regions provide suitable conditions of climate and natural food for forest musk deer and, thus, are ideal for breeding centers. Eight breeding centers are located in Shaanxi Province, a region of the southern Qinling Mountains, with six in Baoji $\left(33^{\circ} 45^{\prime} \mathrm{N}\right.$, $106^{\circ} 40^{\prime}$ E) and two in Hanzhong $\left(33^{\circ} 35^{\prime} \mathrm{N}, 106^{\circ} 49^{\prime}\right.$ E). Five breeding centers are located in Sichuan province, a region on the eastern Tibetan Plateau, with two in Aba $\left(31^{\circ} 24^{\prime} \mathrm{N}\right.$, $\left.103^{\circ} 14^{\prime} \mathrm{E}\right)$ and three in Guangyuan $\left(32^{\circ} 37^{\prime} \mathrm{N}, 104^{\circ} 45^{\prime} \mathrm{E}\right)$.

\section{Morphological analysis}

A total of 674 fresh fecal samples were collected, then each sample was crushed and mixed. Each sample of $5 \mathrm{~g}$ mixed feces was placed in $40 \mathrm{~mL}$ screw-cap plastic vials containing $20 \mathrm{~mL}$ of $2.5 \% \quad(\mathrm{w} / \mathrm{v})$ aqueous potassium dichromate $\left(\mathrm{K}_{2} \mathrm{Cr}_{2} \mathrm{O}_{7}\right)$ solution. Fecal suspensions were then spread out in Petri dishes and incubated at $25{ }^{\circ} \mathrm{C}$ for 2 weeks, allowing time for oocyst sporulation. Following the guidelines of Duszynski \& Wilber [4], we examined oocysts by coverslip flotation in Sheather's sugar solution (S.G. = 1.20), after which they were measured and photographed. Morphological observation and measurements were obtained using oil immersion objectives (Zeiss AX10, Germany), a Nomarski contrast microscope (Zeiss Axio scope 5, Germany) and a Confocal Laser Scanning microscope (Leica DMI 6000 CS, Germany). All measurements (in $\mu \mathrm{m}$ ) are presented as the means followed by their ranges in parentheses, and the oocysts and sporocysts are described following the guidelines of Duszynski \& Wilber [4]. For the calculation, a $95 \%$ confidence interval was used. The prevalence rate, statistical significance were analyzed using Prism GraphPad Prism software (GraphPad, San Diego, CA, USA) as described in Hua et al. [9]. In all cases, $p$ values less than 0.05 were considered significant.

\section{Abbreviation}

As has become standard practice in oocyst descriptions, we use the abbreviations of Duszynski and Wilber [4] in all our species descriptions: $L$, length; $W$, width; $L / W$, length/ width ratio (shape index); M, micropyle; MC, micropyle cap; 
PG, polar granule; OR, oocyst residuum; RB, refractile body in sporozoite; SB, Stieda body in sporocyst; SSB, substieda body; PSB: parastieda body; SR, sporocyst residuum; SZ, sporozoite; $\mathrm{N}$, nucleus of SZ; $95 \% \mathrm{CI}$ : $95 \%$ confidence interval.

\section{Results}

Out of 674 fecal samples evaluated, 226 were from females, 263 from males, and 185 from young individuals. Oocysts that we detected represent six new Eimeria spp. and one or more species were found in 441 or $65 \%$ samples $(95 \%$ CI: $0.62,0.69)$ with no significant difference ( $p=0.85,95 \% \mathrm{CI}:-0.08,0.12$ ) between males $(57 \%, 95 \% \mathrm{CI}: 0.51,0.63)$ and females $(59 \%$, 95\% CI: 0.53, 0.66). However, the prevalence of Eimeria in young individuals $(85 \%, 95 \%$ CI: $0.80,0.90)$ was significantly higher than males $(p<0.01,95 \%$ CI: $-0.38,-0.17)$ and females $(p<0.01,95 \% \mathrm{CI}:-0.36,-0.15)$. Of the positive fecal samples, 195/441 (44\%) were found to harbor only one Eimeria species at the time of sampling, 146/441 (33\%) were infected with two Eimeria species, 73/441 (17\%) had three species, 23/441 (5\%) had four species, and 4/441 (1\%) were concurrently infected with five or more Eimeria species.

In the following lines, we describe six new species from M. berezovskii in China.

\section{Eimeria aquae n. sp. (Figs. 1A, 1B; Fig. 2A)}

\author{
urn:lsid:zoobank.org:act:AC05A343-493E-4021-964C-
} 9440DAFF11EC

Type host: Artiodactyla: Moschidae: Moschus berezovskii Flerov, 1929, Chinese forest musk deer.

Type locality: Hanzhong $\left(33^{\circ} 35^{\prime} \mathrm{N}, 106^{\circ} 49^{\prime} \mathrm{E}\right)$, Shaanxi Province, China.

Other hosts: None to date.

Description of sporulated oocyst: Oocyst shape: ovoid; $L \times W(n=64): 32.0 \times 23.0(27-33 \times 21-26), L / W$ ratio: 1.3 (1.2-1.4); oocyst wall smooth, colourless to pale yellow, $\sim 1.2$ thick, bi-layered; oocyst wall thickest on sides and thinnest at end opposite M; MC: absent; M: present $(n=54), 3.0(0.7-$ 5.8) wide; PG: present as scattered granules of various sizes, $0.5-1.1$ wide; OR: present in some oocysts $(n=7)$ : $\sim 2.0$ (0.5-3.4) wide (Fig. 1B).

Description of sporocyst and sporozoites: Sporocyst shape: elongate-ovoidal; $L \times W(n=62)$ : $14.1 \times 7.5(10-16 \times 5-9)$; $L / W$ ratio: 1.9 (1.5-2.2); SB present; SSB, PSB: both absent; SR: present as small granules disbursed between SZ; SZ banana-shaped with one large RB at its more rounded end, and a second smaller RB in the anterior (more pointed) end; $\mathrm{N}$, when visible, in middle of SZ between RBs.

Prevalence: Oocysts of this morphotype were found in 255/674 (38\%) M. berezovskii, being found in 92/185 (50\%) juveniles, in 90/263 (34\%) adult males, and in 73/226 (32\%) adult females.

Sporulation: Exogenous. Oocysts were shed unsporulated and became completely sporulated after two weeks in $2.5 \%$ $(\mathrm{w} / \mathrm{v})$ potassium dichromate solution $\left(\mathrm{K}_{2} \mathrm{Cr}_{2} \mathrm{O}_{7}\right)$.

Prepatent and patent periods: Unknown.
Site of infection: Unknown, oocysts were recovered from feces after the animals defecated.

Pathogeny: Unknown.

Materials deposited: Photosyntypes [5] of sporulated oocysts are deposited in the Key Laboratory of Non-Invasive Research Technology for Endangered Species, School of Nature Conservation, Beijing Forestry University, Beijing, China, repository number is BFU-E-2, 2020.

Etymology: The species name is derived from the oocysts shape, which resembles a drop of water, and aqua- (L., water, water-like).

Remarks: The oocyst (Table 1) and sporocyst (Table 2) structural data of the other eimerians known to infect Moschus species worldwide, show that sporulated oocysts of E. aquae somewhat resemble those of a morphotype described by Sha et al. [19], which they called E. moschus (now E. dujiangyanensis N. Comb., see below), but the width of their $M$, size of their sporocysts, and shape of their SZs are all different. The length of E. aquae oocysts is similar to that of E. kaii but the width of the latter is much smaller resulting in distinctly different $L / W$ ratios (1.3 vs. 1.5$)$, and the number, size and shape of their PGs are different.

\section{Eimeria dolichocystis n. sp. (Figs. 1C, 1D; Fig. 2B)}

urn:1sid:zoobank.org:act:9F65AF5C-D2C5-48B8-BF75D083D70839C0

Type host: Artiodactyla: Moschidae: Moschus berezovskii Flerov, 1929, Chinese forest musk deer.

Type locality: Guangyuan $\left(32^{\circ} 37^{\prime} \mathrm{N}, 104^{\circ} 45^{\prime} \mathrm{E}\right)$, Sichuan Province, China.

Other hosts: Unknown, none to date.

Description of sporulated oocyst: Oocyst shape: elongated cylindroidal or, ellipsoidal; $L \times W(n=23)$ : $36.6 \times 18.9$ $(29-40 \times 16-20), L / W$ ratio: 2.0 (1.9-2.2); oocyst wall smooth and colorless to pale yellow, $\sim 1.3$ thick, bi-layered; oocyst wall thickest on sides and thinnest at end opposite the M; MC: absent; M: present $(n=13), \sim 2.3(0.9-4.0)$ wide; PG: always one, but a few have two (1.6-1.9 wide); OR: present in some oocysts $(n=4), 1.3(1.2-1.5)$ wide.

Description of sporocyst and sporozoites: Sporocyst shape: elongate ovoidal; $L \times W(n=23): 13.9 \times 7.7(10-18 \times 5-12)$; $L / W$ ratio: 1.8 (1.4-2.6); SB present; SSB, PSB: both absent; SR: present as small granules disbursed between SZ; SZ: sausage-like with one large RB at rounded end of SZ, and sometimes a second, smaller RB in the anterior end; $\mathrm{N}$ of $\mathrm{SZ}$, when visible, between the RBs.

Prevalence: Oocysts of this morphotype were found in 73/ $674(11 \%)$ M. berezovskii, being found in 39/185 (21\%) juveniles, in $15 / 263(6 \%)$ adult males, and in 19/226 (8\%) adult females.

Sporulation: Exogenous. Oocysts were shed unsporulated and become completely sporulated after two weeks in $2.5 \%$ $(\mathrm{w} / \mathrm{v})$ potassium dichromate solution $\left(\mathrm{K}_{2} \mathrm{Cr}_{2} \mathrm{O}_{7}\right)$.

Prepatent and patent periods: Unknown.

Site of infection: Unknown, oocysts were recovered from feces after the animals defecated.

Pathogeny: Unknown. 


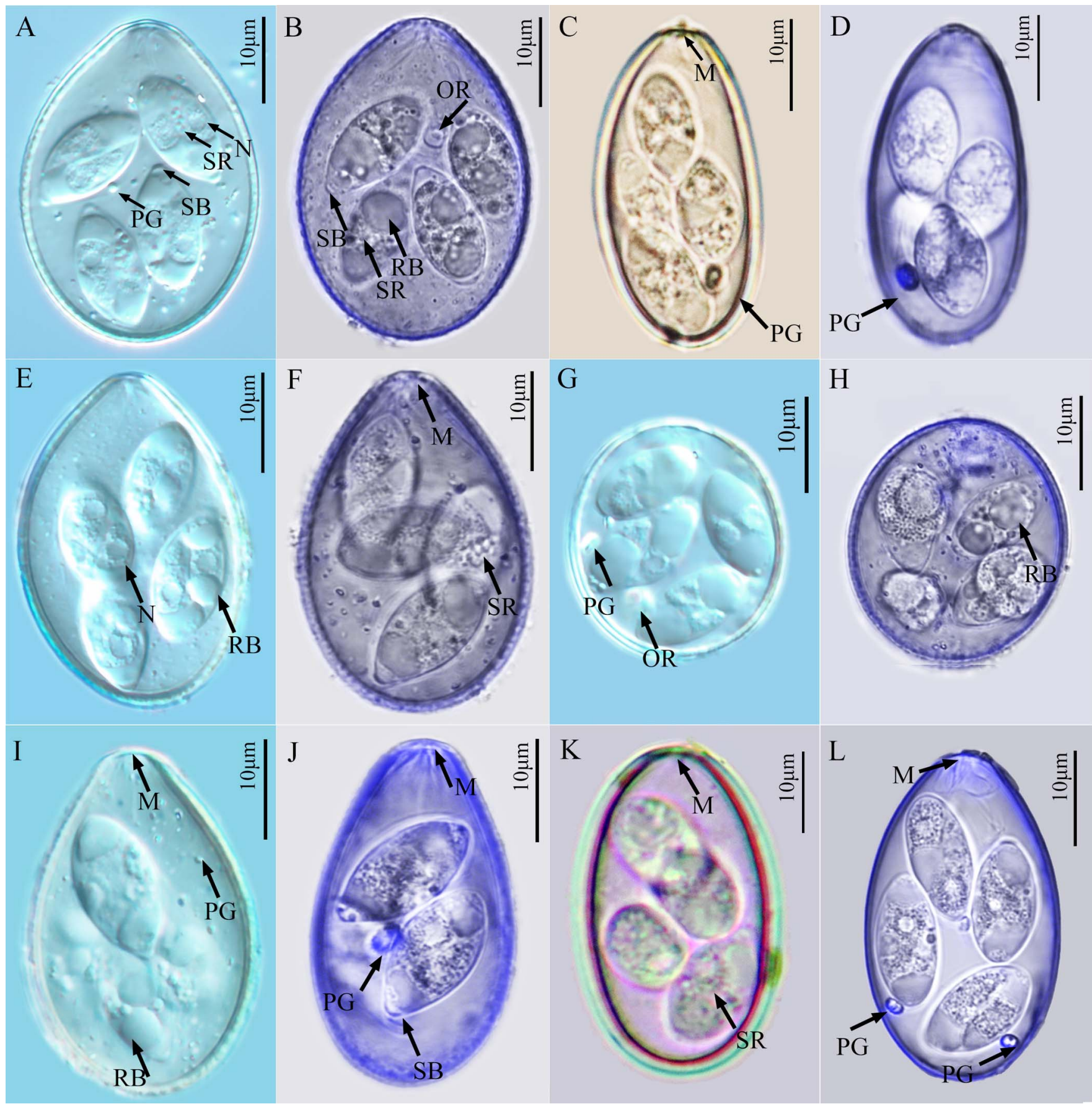

Figure 1. Photomicrographs of the sporulated oocysts of six Eimeria species collected from forest musk deer. A, B. Eimeria aquae n. sp.; C, D. Eimeria dolichocystis n. sp.; E, F. Eimeria fengxianensis n. sp.; G, H. Eimeria helini n. sp.; I, J. Eimeria kaii n. sp.; K, L. Eimeria oocylindrica n. sp.; Figs. A, E, G, I were obtained by differential interference contrast microscopy; Figs. B, D, F, H, J, L were obtained by confocal laser scanning microscopy; Figs. C, K were obtained under standard light microscopy under oil immersion. Abbreviations: M, micropyle; PG, polar granule; OR, oocyst residuum; RB, refractile body in sporozoite; SB, Stieda body on sporocyst; SR, sporocyst residuum; N, nucleus of SZ.

Materials deposited: Photosyntypes [5] of sporulated oocysts are deposited in the Key Laboratory of Non-Invasive Research Technology for Endangered Species, School of Nature Conservation, Beijing Forestry University, Beijing, China, repository number is BFU-E-8, 2020.
Etymology: The species name is derived from the long oocyst shape using dolichol- (Gk., long).

Remarks: The elongated, cylindroidal shape of the oocysts of $E$. dolichocystis is its most distinctive feature and their $L / W$ ratio is the largest of all known and previously described 
A

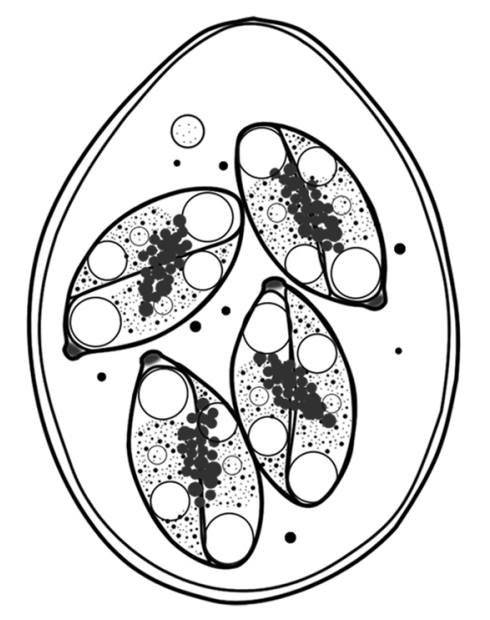

$\mathrm{D}$

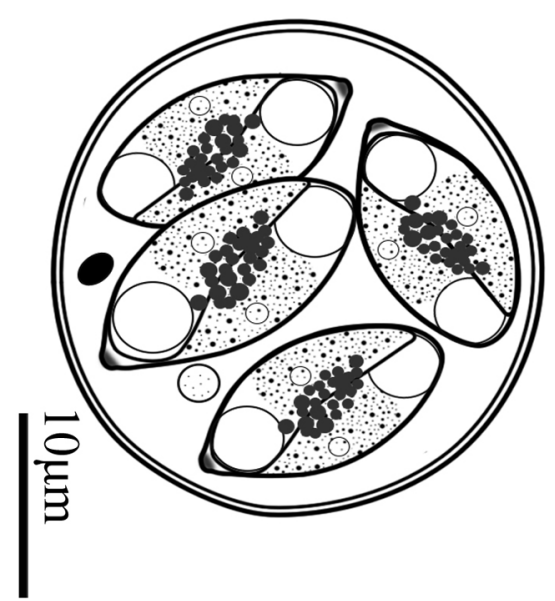

$\mathrm{B}$

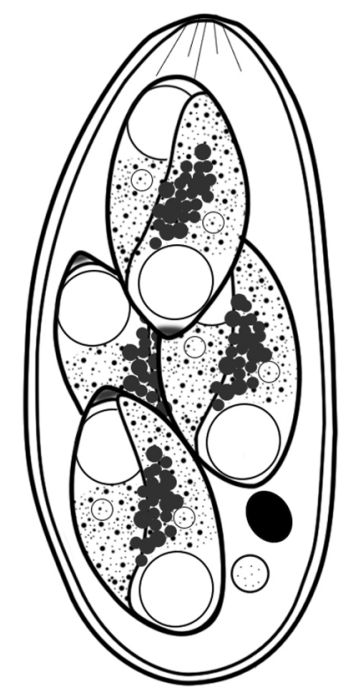

E

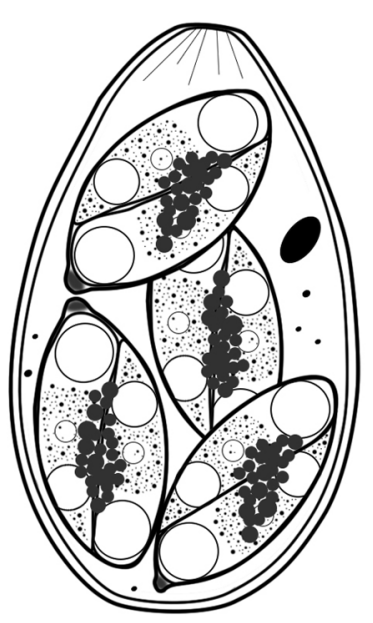

$\mathrm{C}$

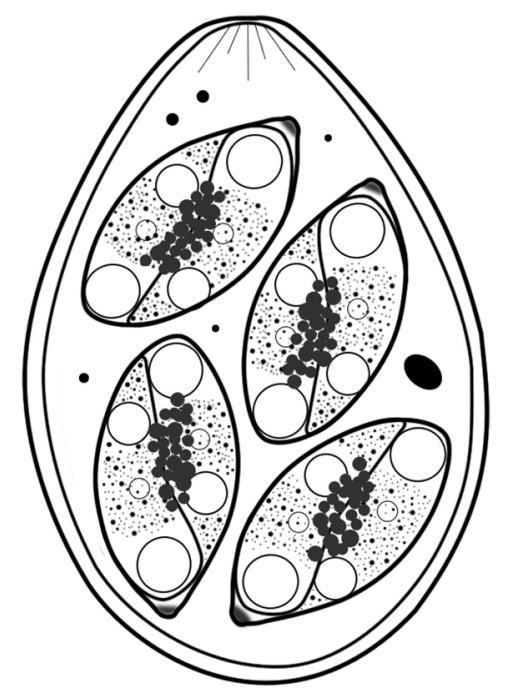

F

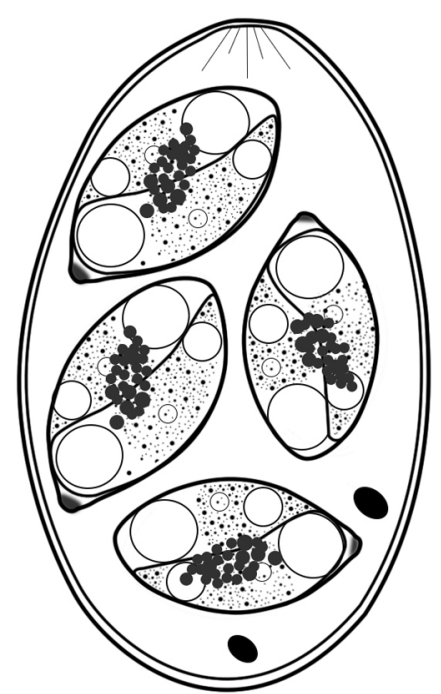

Figure 2. Line drawings of the sporulated oocysts of the six Eimeria species discovered and described from forest musk deer. A. Eimeria aquae n. sp.; B. Eimeria dolichocystis n. sp.; C. Eimeria fengxianensis n. sp.; D. Eimeria helini n. sp.; E. Eimeria kaii n. sp.; F. Eimeria oocylindrica $\mathrm{n}$. sp.

species (Table 1). This feature clearly distinguishes it from all other know eimerians in Moschus.

\section{Eimeria fengxianensis n. sp. (Figs. 1E, 1F; Fig. 2C)}

urn:Isid:zoobank.org:act:D240F705-FB6A-4158-AA12-

\section{FCC0F4100778}

Type host: Artiodactyla: Moschidae: Moschus berezovskii Flerov, 1929, Chinese forest musk deer.

Type locality: Baoji $\left(33^{\circ} 45^{\prime} \mathrm{N}, 106^{\circ} 40^{\prime} \mathrm{E}\right)$, Shaanxi Province, China.

Other hosts: Unknown, none to date.

Description of sporulated oocyst: Oocyst shape: ovoidal; $L \times W(n=31): 36.3 \times 25.2(35-39 \times 24-27), L / W$ ratio: 1.4 (1.4-1.5); oocyst wall smooth and colourless to pale yellow, $\sim 1.6$ thick, bi-layered; oocyst wall thickest on sides and thinnest at end opposite M; MC: absent; M: present $(n=30)$,
2.1 (0.9-5.1) wide; PG: a few, scattered throughout oocyst; PG: present, 0.6-1.0 wide; OR: absent.

Description of sporocyst and sporozoites: Sporocyst shape: elongate-ovoidal; $L \times W(n=27)$ : $13.9 \times 7.3(11-16 \times 6-9)$; $L / W$ ratio: 1.9 (1.6-2.2); SB: present; SSB, PSB: both absent; SR: present as small granules disbursed between SZ; SZ: sausage-like, usually with one large RB at rounded end of SZ and a smaller RB near the more pointed end; $N$ : when visible, in middle of SZ between RBs.

Prevalence: Oocysts of this morphotype were found in 45/674 (7\%) M. berezovskii, being found in 19/185 (10\%) juveniles, in 11/263 (4\%) adult males, and in 15/226 (7\%) adult females.

Sporulation: Exogenous. Oocysts were shed unsporulated and became completely sporulated after 2 weeks in $2.5 \%$ (w/v) potassium dichromate solution $\left(\mathrm{K}_{2} \mathrm{Cr}_{2} \mathrm{O}_{7}\right)$.

Prepatent and patent periods: Unknown. 
Table 1. Defining structural characters of the sporulated oocysts of all Eimeria species known from all seven musk deer species (Moschidae: Moschus spp.) worldwide.

\begin{tabular}{|c|c|c|c|c|c|c|c|c|}
\hline Host sp./Eimeria sp. & Shape $^{1}$ & Wall $^{2}$ & $\begin{array}{l}L \times W \\
\text { (range) }\end{array}$ & $\begin{array}{l}L \times W \\
\text { (ratio) }\end{array}$ & $\begin{array}{l}\text { Micropyle }^{3} \\
\text { (width) }\end{array}$ & $\begin{array}{l}\text { Micropyle } \\
\text { Cap (size) }\end{array}$ & $\begin{array}{l}\text { Residuum } \\
\text { (width) }\end{array}$ & $\begin{array}{c}\text { Polar } \\
\text { Granule/\# } \\
(\text { size })\end{array}$ \\
\hline \multicolumn{9}{|l|}{ M. berezovskii } \\
\hline E. aquae & $\mathrm{O}$ & $\begin{array}{c}\mathrm{S} / 2 \\
(1.2)\end{array}$ & $\begin{aligned} 32.0 & \times 23.0 \\
(27-33 & \times 21-26)\end{aligned}$ & 1.3 & $\begin{array}{c}+ \\
(0.7-5.8)\end{array}$ & - & $+/-(0.5-3.4)$ & $\begin{array}{c}+/ \mathrm{a} \text { few } \\
(0.5-1.1)\end{array}$ \\
\hline E. dolichocystis & $\mathrm{C} / \mathrm{E}$ & $\begin{array}{c}\mathrm{S} / 2 \\
(1.3)\end{array}$ & $\begin{aligned} 36.6 & \times 18.9 \\
(29-40 & \times 16-20)\end{aligned}$ & 2.0 & $\begin{array}{c}+ \\
(0.9-4.0)\end{array}$ & - & $\stackrel{+/-}{(1.2-1.5)}$ & $\begin{array}{c}+/ 1-2 \\
(1.6-1.9)\end{array}$ \\
\hline E. fengxianensis & $\mathrm{O}$ & $\begin{array}{c}\mathrm{S} / 2 \\
(1.6)\end{array}$ & $\begin{aligned} 36.3 & \times 25.2 \\
(35-39 & \times 24-27)\end{aligned}$ & 1.4 & $\begin{array}{c}+ \\
(0.9-5.1)\end{array}$ & - & - & $\begin{array}{c}+/ \mathrm{a} \text { few or } 1 \\
(0.6-1.0)\end{array}$ \\
\hline E. helini & $\mathrm{S} / \mathrm{SS}$ & $\begin{array}{c}\mathrm{S} / 2 \\
(1.1)\end{array}$ & $\begin{aligned} 27.0 & \times 24.1 \\
(20-30 & \times 16-27)\end{aligned}$ & 1.1 & - & - & $\begin{array}{c}+ \\
(0.3-3.0)\end{array}$ & $\begin{array}{c}+/ 1 \\
(1.9-2.6)\end{array}$ \\
\hline E. jinfengshanenisis & $\mathrm{O}$ & $\begin{array}{c}\mathrm{S} / 2 \\
(0.5-0.8)\end{array}$ & $\begin{array}{c}28.1 \times 18.3 \\
(25-32.5 \times 17.5-18.5)\end{array}$ & 1.6 & $\begin{array}{c}+ \\
\text { (Inc.) }\end{array}$ & - & - & - \\
\hline E. dujiangyanensis & $\mathrm{O}$ & $\mathrm{S} / 2$ & $\begin{array}{c}35.2 \times 26.9 \\
(32.5-37.5 \times 25-30)\end{array}$ & 1.3 & $\stackrel{+}{+}$ & - & - & - \\
\hline E. kaii & $\mathrm{O}$ & $\begin{array}{c}\mathrm{S} / 2 \\
(1.2)\end{array}$ & $\begin{aligned} 33.2 & \times 20.7 \\
(32-37 & \times 19-24)\end{aligned}$ & 1.5 & $\begin{array}{c}+ \\
(0.9-4.9)\end{array}$ & - & - & $\begin{array}{c}+/ \mathrm{a} \text { few or } 1-2 \\
\quad(0.6-2.8)\end{array}$ \\
\hline E. oocylindrica & $\mathrm{C} / \mathrm{E} / \mathrm{O}$ & $\begin{array}{c}\mathrm{S} / 2 \\
(1.3)\end{array}$ & $\begin{aligned} 36.0 & \times 21.4 \\
(33-41 & \times 19-26)\end{aligned}$ & 1.7 & $\begin{array}{c}+ \\
(0.8-6.7)\end{array}$ & - & - & $\begin{array}{c}+/ 1-2 \\
(1.6-2.0)\end{array}$ \\
\hline \multicolumn{9}{|l|}{ M. moschiferus } \\
\hline E. moschus & $\mathrm{O}$ & $\mathrm{S} / 2$ & $\begin{aligned} 27.4 & \times 20.9 \\
(20-31 & \times 15-23)\end{aligned}$ & 1.3 & $\begin{array}{c}+ \\
(6.6)\end{array}$ & - & - & - \\
\hline E. sajanica & $\mathrm{S} / \mathrm{SS}$ & $\mathrm{S} / 2$ & $\begin{array}{c}20.7 \times 18.3 \\
(18-23 \times 16.5-20)\end{array}$ & 1.1 & - & - & - & - \\
\hline
\end{tabular}

${ }^{1} \mathrm{C}=$ Cylindroidal; $\mathrm{E}=$ Ellipsoidal; $\mathrm{O}=$ Ovoidal (egg-shaped); $\mathrm{S}=$ Spheroidal (round); $\mathrm{SS}=$ Subspheroidal.

${ }^{2}$ Oocyst wall characteristics: $\mathrm{S}=$ Smooth or $\mathrm{R}=$ Rough/No. of layers (thickness).

${ }^{3}$ Inc. $=$ Micropyle is present but inconspicuous.

Site of infection: Unknown, oocysts were recovered from feces after the animals defecated.

Pathogeny: Unknown.

Materials deposited: Photosyntypes [5] of sporulated oocysts are deposited in the Key Laboratory of Non-Invasive Research Technology for Endangered Species, School of Nature Conservation, Beijing Forestry University, Beijing, China, repository number is BFU-E-6, 2020.

Etymology: Fengxian (Shaanxi Province, China) is the hometown of forest musk deer in China. The species name is derived from this town's name and -ensis (L., belonging to). The name is to thank the local people for their efforts to protect the forest musk deer.

Remarks: The sporulated oocysts of E. fengxianensis are similar to those of E. aquae (Tables 1,2); however, there are some subtle differences that we believe are constant and can help one distinguish between the two species. Sporulated oocysts of the former are larger than those of $E$. aquae $(36 \times 25[35-39 \times 24-27]$ vs. $32 \times 23$ [27-33 × 21-26]), they always have a much thicker oocyst wall (1.6 vs. 1.2), slightly larger $L / W$ ratio (1.4 vs. 1.3), and they lack any remnant of either PG and/or OR, which some of the oocysts of E. aquae often display as 1, 2, or more spheroidal bodies (cf. Figs 1E, $1 \mathrm{~F}$ vs. Figs 1A, 1B).

\section{Eimeria helini n. sp. (Figs. 1G, 1H; Fig. 2D)}

urn:Isid:zoobank.org:act:7B58FD5A-2EE0-4FD7-AC094F73ED4ECB06
Type host: Artiodactyla: Moschidae: Moschus berezovskii Flerov, 1929, Chinese forest musk deer.

Type locality: Aba $\left(31^{\circ} 24^{\prime} \mathrm{N}, 103^{\circ} 14^{\prime}\right.$ E), Sichuan Province, China.

Other hosts: Unknown, none to date.

Description of sporulated oocyst: Oocyst shape: spheroidal to subspheroidal; $L \times W(n=9): 27.0 \times 24.1(20-30 \times 16-27)$, $L / W$ ratio: 1.1 (1-1.3); oocyst wall smooth and colorless to pale yellow, $\sim 1.1$ thick, bi-layered; oocyst wall that may thin slightly at one end; M, MC: both absent; PG: always one present (1.9-2.6 wide); OR: present $(n=2)$ : 0.3-3.2 wide.

Description of sporocyst and sporozoites: Sporocyst shape: elongate ovoidal; $L \times W(n=9): 13.5 \times 7.7(9-16 \times 6-10)$; $L / W$ ratio: 1.8 (1.4-2.0); SB present; SSB, PSB: both absent; SR: present as small granules disbursed between SZ; SZ: sausage-like, usually with one large RB at more rounded end of SZ and sometimes a second, smaller RB is seen in the more pointed end; N: when visible, in middle of SZ between RBs.

Prevalence: Oocysts of this morphotype were found in 159/674 (24\%) M. berezovskii, being found in 53/185 (29\%) juveniles, in 60/263 (23\%) adult males, and in 46/226 (20\%) adult females.

Sporulation: Exogenous. Oocysts were shed unsporulated and they completely sporulated after 2 weeks in $2.5 \%(\mathrm{w} / \mathrm{v})$ potassium dichromate solution $\left(\mathrm{K}_{2} \mathrm{Cr}_{2} \mathrm{O}_{7}\right)$.

Prepatent and patent periods: Unknown.

Site of infection: Unknown, oocysts were recovered from feces after the animals defecated.

Pathogeny: Unknown. 
Table 2. Defining structural characters of the sporocysts/sporozoites of all Eimeria species known from all seven musk deer species (Moschidae: Moschus spp.) worldwide.

\begin{tabular}{|c|c|c|c|c|c|c|c|c|}
\hline Host sp./Eimeria $\mathrm{sp}$. & Shape $^{1}$ & $L \times W$ (range) & $L \times W$ (ratio) & $\begin{array}{c}\text { Stieda/ } \\
\text { Substieda/ } \\
\text { Parastieda } \\
\text { bodies }\end{array}$ & $\begin{array}{l}\text { Residuum } \\
\text { (type/size) }^{2}\end{array}$ & $\begin{array}{c}\text { Refractile } \\
\text { Bodies (No.) }\end{array}$ & SZ Shape & $\mathrm{SZ} \mathrm{N}^{4}$ \\
\hline \multicolumn{9}{|l|}{ M. berezovskii } \\
\hline E. aquae & $\mathrm{E} / \mathrm{O}$ & $\begin{array}{c}14.1 \times 7.5 \\
(10-16 \times 5-9)\end{array}$ & $\begin{array}{c}1.9 \\
(1.5-2.2)\end{array}$ & $+/-1-$ & $\begin{array}{c}+ \\
(\mathrm{SG})\end{array}$ & $\stackrel{+}{+}$ & Banana-like & $\begin{array}{l}+ \\
\mathrm{C}\end{array}$ \\
\hline E. dolichocystis & $\mathrm{E} / \mathrm{O}$ & $\begin{array}{c}13.9 \times 7.7 \\
(10-18 \times 5-12)\end{array}$ & $\begin{array}{c}1.8 \\
(1.4-2.6)\end{array}$ & $+/-1-$ & $\begin{array}{c}+ \\
(\mathrm{SG})\end{array}$ & $\stackrel{+}{(1, \mathrm{~L})}$ & Sausage-like & $\begin{array}{l}+/- \\
\mathrm{C}\end{array}$ \\
\hline E. fengxianensis & $\mathrm{E} / \mathrm{O}$ & $\begin{array}{c}13.9 \times 7.3 \\
(11-16 \times 6-9)\end{array}$ & $\begin{array}{c}1.9 \\
(1.6-2.2)\end{array}$ & $+/-/-$ & $\begin{array}{c}+ \\
(\mathrm{SG})\end{array}$ & $\stackrel{+}{+}$ & Sausage-like & $\stackrel{+/-}{\mathrm{C}}$ \\
\hline E. helini & $\mathrm{E} / \mathrm{O}$ & $\begin{array}{c}13.5 \times 7.7 \\
(9-16 \times 6-10)\end{array}$ & $\begin{array}{c}1.8 \\
(1.4-2.0)\end{array}$ & $+/-I-$ & $\begin{array}{c}+ \\
(\mathrm{SG})\end{array}$ & $\stackrel{+}{+}$ & Sausage-like & $+/-$ \\
\hline E. jinfengshanenisis & $\mathrm{E}$ & $\begin{array}{c}11.1 \times 5.9 \\
(10-11 \times 5-7)\end{array}$ & $\begin{array}{c}1.9 \\
(1.7-2.0)\end{array}$ & $-/-I-$ & $\begin{array}{l}+ \\
(\mathrm{SG})\end{array}$ & $(1,+$ & Banana-like & - \\
\hline E. dujiangyanensis & S & $\begin{array}{c}17.5 \times 8.2 \\
(16-20 \times 7.5-10)\end{array}$ & $\begin{array}{c}2.1 \\
(1.9-2.3)\end{array}$ & $-/-1-$ & $\begin{array}{c}+ \\
(\mathrm{SG})\end{array}$ & $\stackrel{+}{(1, \mathrm{~L})}$ & Sausage-like & - \\
\hline E. kaii & $\mathrm{E} / \mathrm{O}$ & $\begin{array}{c}14.4 \times 7.5 \\
(12-16 \times 6-8)\end{array}$ & $\begin{array}{c}1.9 \\
(1.6-2.2)\end{array}$ & $+/-1-$ & $\begin{array}{c}+ \\
(\mathrm{SG})\end{array}$ & $\stackrel{+}{+}$ & Banana-like & $\stackrel{+/-}{\mathrm{C}}$ \\
\hline E. oocylindrica & $\mathrm{E} / \mathrm{O}$ & $\begin{array}{c}13.8 \times 7.7 \\
(11-16 \times 6-9.5)\end{array}$ & $\begin{array}{c}1.8 \\
(1.5-2.2)\end{array}$ & $+/-1-$ & $\begin{array}{c}+ \\
(\mathrm{SG})\end{array}$ & $\stackrel{+}{+}$ & Sausage-like & $\begin{array}{l}+/- \\
\mathrm{C}\end{array}$ \\
\hline \multicolumn{9}{|l|}{ M. moschiferus } \\
\hline E. moschus & $\mathrm{E}$ & $\begin{array}{l}\text { Means not given } \\
(10-10.5 \times 5-7)\end{array}$ & Not given & $-I-I-$ & $\begin{array}{c}+ \\
(\mathrm{SG})\end{array}$ & $\stackrel{+}{(1, \mathrm{Sm})}$ & Banana-like & - \\
\hline E. sajanica & E & $\begin{array}{l}\text { Means not given } \\
(5-10 \times 3-5)\end{array}$ & 1.1 & $-/-1-$ & $\begin{array}{c}+ \\
(\mathrm{SG})\end{array}$ & $\stackrel{+}{(1, \mathrm{Sm})}$ & Banana-like & - \\
\hline
\end{tabular}

${ }^{1} \mathrm{E}=$ Ellipsoidal; E/O = Elongate-ovoidal (1 end rounded, 1 end pointed slightly); $\mathrm{S}=$ Spindle-shaped.

${ }^{2}$ Sporocyst residuum: Shape, consistency ( $\mathrm{SG}=$ scattered granules; $\mathrm{CM}=$ compact mass).

${ }^{3}$ Refractile bodies of SZ: Number, general size $(\mathrm{L}=$ large at rounded end; $\mathrm{S}=$ smaller at pointed end; $\mathrm{Sm}=$ small at rounded end $)$.

${ }^{4}$ Sporozoite (SZ) nucleus $(\mathrm{N})$ : visible $(+)$, not visible $(-)$; location $(\mathrm{C}=$ central in $\mathrm{SZ} ; \mathrm{W}=$ wide end of SZ; $\mathrm{P}=$ pointed end of SZ).

Materials deposited: Photosyntypes [5] of sporulated oocysts are deposited in the Key Laboratory of Non-Invasive Research Technology for Endangered Species, School of Nature Conservation, Beijing Forestry University, Beijing, China, repository number is BFU-E-9, 2020.

Etymology: The species name is given in honor of Helin Sheng, a retired professor at East China Normal University, who has been devoted to musk deer conservation and research for more than 30 years.

Remarks: The spheroidal to subspheroidal shape of the sporulated oocysts is a distinctive feature in E. helini that allows it to be distinguished from all other eimerians now known to infect Moschus species.

\section{Eimeria kaii n. sp. (Fig. 1I, 1J; Fig. 2E)}

urn:lsid:zoobank.org:act:46620F9C-97ED-4B63-A16C-

\section{E1B376EE6DC}

Type host: Artiodactyla: Moschidae: Moschus berezovskii Flerov, 1929, Chinese forest musk deer.

Type locality: Baoji $\left(33^{\circ} 45^{\prime} \mathrm{N}, 106^{\circ} 40^{\prime} \mathrm{E}\right)$, Shaanxi Province, China.

Other localities: Hanzhong $\left(33^{\circ} 35^{\prime} \mathrm{N}, 106^{\circ} 49^{\prime} \mathrm{E}\right)$, Shaanxi Province, China. Aba ( $\left(31^{\circ} 24^{\prime} \mathrm{N}, 103^{\circ} 14^{\prime} \mathrm{E}\right)$, Sichuan Province, China. Guangyuan $\left(32^{\circ} 37^{\prime}\right.$ N, $104^{\circ} 45^{\prime}$ E), Sichuan Province, China.

Other hosts: Unknown, none to date.
Description of sporulated oocyst: Oocyst shape: ovoidal; $L \times W(n=94): 33.2 \times 20.7(32-37 \times 19-24), L / W$ ratio: 1.5 (1.5-1.7); oocyst wall smooth and colourless to pale yellow, $\sim 1.2$ thick, bi-layered; oocyst wall thickest on sides and thinnest at end opposite the M; MC: absent; M: present $(n=81)$ : 1.9 $(0.9-4.9)$ wide; PG: present only as a few scattered granules or 1-2 spheroidal bodies, 0.6-2.8 wide; OR: absent.

Description of sporocyst and sporozoites: Sporocyst shape: elongate-ovoidal; $L \times W(n=92): 14.4 \times 7.5(12-16 \times 6-8)$; $L / W$ ratio: 1.9 (1.6-2.2); SB: present; SSB, PSB: both absent; SR: present as small granules disbursed between SZ; SZ: usually with one large RB at more rounded end of SZ, and a second smaller RB in the thinner end of the SZ; N: when visible, in middle of SZ between RBs.

Prevalence: Oocysts of this morphotype were found in 174/674 (26\%) M. berezovskii, being found in 79/185 (43\%) juveniles, in 42/263 (16\%) adult males, and in 53/226 (23\%) adult females.

Sporulation: Exogenous. Oocysts were shed unsporulated and became completely sporulated after 2 weeks in $2.5 \%(\mathrm{w} / \mathrm{v})$ potassium dichromate solution $\left(\mathrm{K}_{2} \mathrm{Cr}_{2} \mathrm{O}_{7}\right)$.

Prepatent and patent periods: Unknown.

Site of infection: Unknown, oocysts were recovered from feces after the animals defecated.

Pathogeny: Unknown.

Materials deposited: Photosyntypes [5] of sporulated oocysts are deposited in the Key Laboratory of Non-Invasive 
Research Technology for Endangered Species, School of Nature Conservation, Beijing Forestry University, Beijing, China, repository number is BFU-E-4, 2020.

Etymology: This species was named in honor of Kai Li, a professor of the Key Laboratory of Non-Invasive Research Technology for Endangered Species, School of Nature Conservation, Beijing Forestry University, Beijing, China, in recognition of his numerous contributions to our understanding of wildlife conservation and research.

Remarks: The $L / W$ ratio of sporulated oocysts of this species is similar as the $L / W$ ratio of E. jinfengshanenisis. However, many features truly distinguish them from each other including oocyst and sporocyst size ranges, the number and shape of their RBs in the SZ, and the presence of a SB in the sporocysts of $E$. kaii that the sporocysts of or absent of E. jinfengshanenisis lack (Tables 1, 2).

\section{Eimeria oocylindrica n. sp. (Figs. 1K, 1L; Fig. 2F)}

\author{
urn:lsid:zoobank.org:act:4DC3D38E-BBB8-4A70-B98D-
} 9CC7F150DD82

Type host: Artiodactyla: Moschidae: Moschus berezovskii Flerov, 1929, Chinese forest musk deer.

Type locality: Guangyuan $\left(32^{\circ} 37^{\prime} \mathrm{N}, 104^{\circ} 45^{\prime} \mathrm{E}\right)$, Sichuan Province, China.

Other hosts: Unknown, none to date.

Description of sporulated oocyst: Oocyst shape: cylindroidal, ellipsoid, to elongate ovoidal; $L \times W(n=27)$ : $36.0 \times 21.4(33-41 \times 19-26), L / W$ ratio: 1.7 (1.6-1.8); oocyst wall smooth and colorless to pale yellow, $\sim 1.3$ thick, bi-layered; oocyst wall thickest on sides and thinnest at end opposite M; MC: absent; M: present $(n=23), \sim 2.6(0.8-6.7)$ wide; 1 or 2 obvious PG present (1.6-2.0 wide), OR absent.

Description of sporocyst and sporozoites: Sporocyst shape: elongate ovoidal; $L \times W(n=25)$ : $13.8 \times 7.7(11-16 \times 6-9.5)$; $L / W$ ratio: 1.8 (1.5-2.2); SB present; SSB, PSB: both absent; SR: present as small granules disbursed between SZ; SZ sausage-shaped with large $\mathrm{RB}$ at more rounded end and a smaller RB at the more pointed end; $\mathrm{N}$, when visible, in middle of $\mathrm{SZ}$ between RBs.

Prevalence: Oocysts of this morphotype were found in 113/674 (17\%) M. berezovskii, being found in 49/185 (26\%) juveniles, in 26/263 (10\%) adult males, and in 38/226 (17\%) adult females.

Sporulation: Exogenous. Oocysts were shed unsporulated and became completely sporulated after 2 weeks in $2.5 \%$ (w/v) potassium dichromate solution $\left(\mathrm{K}_{2} \mathrm{Cr}_{2} \mathrm{O}_{7}\right)$.

Prepatent and patent periods: Unknown.

Site of infection: Unknown, oocysts were recovered from feces after the animals defecated.

Pathogeny: Unknown.

Materials deposited: Photosyntypes [5] of sporulated oocysts are deposited in the Key Laboratory of Non-Invasive Research Technology for Endangered Species, School of Nature Conservation, Beijing Forestry University, Beijing, China, repository number is BFU-E-7, 2020.

Etymology: The species name is derived from oocyst shape based on oocyst and cylindr- (Gk., cylinder).
Remarks: The sporulated oocysts of this species are similar in shape to those of E. jinfengshanenisis described by Sha et al. [19] but their oocyst dimensions are very different (Table 1). The size range of $E$. oocylindrica oocyst is most similar to those of $E$. dolichocystis and E. fengxianensis. They differ from those of $E$. dolichocystis by having a much smaller $L / W$ ratio (1.7 vs. 2.0), and they lack an OR which is present in oocysts of E. dolichocystis (Table 1). They differ from those of E. fengxianensis by having a different shape, a thinner oocyst wall, a larger $L / W$ ratio (Table 1 ) and two RBs vs. one RB in the SZ of E. fengxianensis (Table 2).

Four species of Eimeria were already described from Moschus berezovskii.

\section{Eimeria jinfengshanenisis Sha, Zhang, Cai, Wang and Liu, 1994}

Type host: Artiodactyla: Moschidae: Moschus berezovskii Flerov, 1929, Chinese forest musk deer.

Remarks: Sha et al. [19] published a short note describing two new Eimeria species from $M$. berezovskii they sampled in Sichuan Province, China. The oocysts they described were broadly ovoidal and measured, $28.1 \times 18.3(25-32.5 \times$ 17.5-18.5); $L / W$ ratio: 1.6 (sic) (1.4-1.8) with a thin, 2-layered oocyst wall, $\sim 0.5-0.8$ thick and an inconspicuous $\mathrm{M}$ and lacking OR and PG. Their sporocysts were ellipsoidal, $11.1 \times 5.9$ $(10-11 \times 5-7) ; L / W$ ratio: 1.9 (1.7-2.0), without $\mathrm{SB}, \mathrm{SSB}$, or PSB, but a SR of small granules between SZ was present (see Tables 1, 2 for other details). They compared the oocysts of this species to those of $E$. faurei from the domestic sheep because they thought that theirs were the first two eimerians ever found in any species of Moschus. Clearly, they were unaware of the paper by Matschoulsky [15] who earlier had described two eimerians from Moschus moschiferus L., 1758, the Siberian musk deer.

The sporulated oocysts of this species are among the smallest of all eimerians now known from Moschus species and clearly differs from the others in several structural features (see Tables 1,2). One obvious structural feature that is missing in the work of Sha et al. [19] is that the sporocysts of this species lack a SB, both in their written description and line drawing. We suspect that this was a lapsus calami on their part since very few (true) eimerians in the Artiodactyla are reported without a SB (and some of these are also in error).

\section{Eimeria moschus Matschoulsky, 1947}

Type host: Artiodactyla: Moschidae: Moschus berezovskii Flerov, 1929, Chinese forest musk deer.

Remarks: As far as we know, Matschoulsky [15] published the first paper identifying and (partially) describing the oocysts of two Eimeria parasites in musk deer, but the paper was in an obscure journal and most scholars who have summarized the coccidia known in Artiodactyla and/or in Moschus, as indicated by Pellérdy [17], Levine and Ivens [11, 12], Levine [10], Sha et al. [19], were unaware of or unable to obtain a copy of Matschoulsky's in 1947 [15]. Fortunately, we have a copy of his paper in our archive and our best translation of that paper 
(from Russian) tells us that Matschoulsky in 1947 [15] said, "We studied feces of musk-deer, from Kunkien region, and found two different species of coccidia," which he named E. moschus and E. sajanica. Later authors [11, 12, 17], who did not see Matschoulsky's original paper, refer to information given by Svanbaev [22] who referred to Matchoulsky's earlier work, did not mention E. moschus, and seemed to presume that E. sajanica was found in Saiga tatarica "found in Asian territory of the Soviet Union." In 1947, Matschoulsky [15] said these oocysts from musk deer were ovoidal with a two-layered wall, a well-defined $\mathrm{M}$ up to 6.6 wide, and measured $27.4 \times 20.9(20-31 \times 15-23) ; L / W$ ratio: $1.3 ;$ OR, PG: both absent. Sporocysts were ellipsoidal, 10-10.5 × 5-7 (means not given) and SB, SSB, PSB were all absent while SR was present as scattered small granules and SZ had one small RB at its more rounded end (line drawing). Matschoulsky [15] mentioned neither the host species name nor the specific locality from which the oocysts were collected, but he did state the two species he was describing were from a musk deer so we must presume the host was $M$. moschiferus, which is found in Siberia. The description of this species is marginal by even the most lenient current standard, but Matschoulsky [15] did provide a line drawing to illustrate the specimen he described. We believe the most prudent thing to do now is to accept his name (since it has priority) and description until future studies can confirm or dispute its existence.

\section{Eimeria dujiangyanensis (Sha et al., 1994) n. nom.}

urn:lsid:zoobank.org:act:8E81F0A4-9E6A-4AB1-ABC6FBD13CC54963

Synonym: Eimeria moschus Sha, Zhang, Cai, Wang and Liu 1994.

Type host: Artiodactyla: Moschidae: Moschus berezovskii Flerov, 1929, Chinese forest musk deer.

Remarks: Sha et al. [19] did not read Matschoulsky's [15] paper using the same name (Eimeria moschus) for an eimerian they described from M. berezovskii in China. Their oocysts had ovoidal sporulated oocysts that measured, $35.2 \times 26.9$ (32.5-37.5 × 25-30); $L / W$ ratio: 1.3 ; M: present, $\sim 6-7$ wide; OR, PG: both absent. Their sporocysts were spindle-shaped, pointed at both ends, $17.5 \times 8.2(16-20 \times 7.5-10) ; L / W$ ratio: 2.1 (1.9-2.3); SB, SSB, PSB: all absent; SR: present as scattered small granules between SZ; SZ: with one RB at its more rounded end (line drawing).

Etymology: We propose a new name for the species to avoid synonymy. The new species name is derived from the name of the location within Sichuan Province where Sha et al. (1994) found this species and -ensis (Latin, belonging to).

\section{Eimeria sajanica Matschoulsky, 1947}

Type host: Artiodactyla: Moschidae: Moschus moschiferus L., 1758, Siberian musk deer.

Remarks: Matschoulsky [15] published the first paper identifying and (partially) describing two eimerian parasites in musk deer but the paper was in an obscure journal and most scholars who have summarized the coccidia known in Artiodactyles and/or in Moschus, as indicated by Pellérdy [17], Levine and Ivens [11, 12], Levine [10], Sha et al. [19], either were unaware of, or were unable to obtain a copy of his paper in 1947 [15]. Our translation (from Russian) of that original paper [15] is: "We studied feces of musk-deer, from Kunkien region, and found two different species of coccidia," which he named E. moschus and E. sajanica. Later authors, as noted above, referred to information given by Svanbaev [22], who mentioned Matchoulsky's work [15], but presumed that E. sajanica was found in Saiga tatarica "in Asian territory of the Soviet Union." However, if we trust that Matschoulsky [15] said these oocysts were from musk deer, then they must be from M. moschiferus, the Siberian musk deer. Matschoulsky [15] said these oocysts from the musk deer were ovoidal to round with a two-layered wall, but lacked a M, and measured $20.7 \times 18.3(18-23 \times$ 16.5-20); $L / W$ ratio: 1.1 ; OR, PG: both absent. Sporocysts were ellipsoidal, 5-10 × 3-5 (means not given); SB, SSB, PSB: all absent; SR: present as scattered small granules between SZ; SZ: with one small $\mathrm{RB}$ at more rounded end (line drawing). The description of this species is marginal by even the most lenient current standard, but Matschoulsky [15] provided a line drawing to illustrate the specimen he described. We believe the most prudent thing to do now is to accept his name and description until future studies can confirm or dispute its existence.

\section{Discussion}

In summary, 10 species of Eimeria are now known to parasitize two of the seven extant Moschus species; the remaining five Moschus species have never been examined for coccidian oocysts. These 10 coccidians include the six new species described here from M. berezovskii (E. aquae, E. dolichocystis, E. fengxianensis, E. helini, E. kaii, E. oocylindrica), two species described by Sha et al. [19], also from M. berezovskii (E. dujiangyanensis, E. jinfengshanenisis), and the first two species that were (partially) described by Matschoulsky [15] from M. moschiferus (E. moschus, E. sajanica). This is the first comprehensive report of the coccidian species known from all forest musk deer (Moschus spp.).

Our study demonstrated a high prevalence $(65 \%)$ of six Eimeria species in the forest musk deer we sampled, especially in juveniles $(85 \%)$, which is similar to infection rates found by other workers in China [2,3]. The infection prevalence of Eimeria between female and male adults was not significantly different in our research, which had been observed in Cai et al. [2], when they compared the prevalence of Eimeria oocysts between males (46\%) and females (45\%) in 2016, and did not find any difference in genders $(p>0.05)$. In all fecal samples, E. aquae was the most prevalent species $(38 \%$, 255/674), while the other five eimerians we discovered have lower prevalence in these endangered deer: E. kaii $26 \%$ (174/674), E. helini 24\% (159/674), E. oocylindrica $17 \%$ (113/674), E. dolichocystis $11 \%$ (73/674), and E. fengxianensis $7 \%$ (45/674). Of all positive samples, $60 \%$ were infected with multiple Eimeria species. These results suggest to us that Eimeria spp. in these musk deer may be the main risk factor in limiting their health and contribute as the leading negative effect on juvenile musk deer survival. We suggest that 
integrated strategies are essential to prevent and/or at least control coccidial infection in these populations.

Unfortunately, this is the sum total of our knowledge about the biology of all species in the Eimeriidae, now known to infect musk deer. We know nothing about any of their endogenous stages (merogony and the number of generations, merozoites produced at each stage, micro- and macrogametocytes, fertilization, oocyst wall formation) or the cells and locations of these stages in infected cells or even within the gastrointestinal tract (or elsewhere?); we know nothing about the pathology each of these eimerians may cause in musk deer and whether some are more pathogenic than others; we know nothing about how long these eimerians can persist within their hosts (prepatent and patent periods); there have not yet been any cross-transmission studies with any of the 10 known Eimeria species so we do not know if each can infect other wild or domestic Artiodactyla; we know nothing about the host's immune response to each of these eimerians or if previous infection produces lasting or only transient immunity to that species or even to other species; we do know that many of the 10 known eimerians have sporulated oocysts that share many similarities, but there have not yet been any genes sequenced of any of these oocysts and, thus, no phylogenetic analyses have been possible to determine whether or not these oocysts, or certain combinations thereof, represent 10 or perhaps fewer real species. Clearly, we are only at the discovery stage and there is a lot more work to be done before we can gain any real understanding of the biology and consequences of Eimeria species infections in our endangered and protected musk deer.

\section{Conclusion}

In captivity, the confined areas and high stress would accelerate host susceptibility to parasites. Additionally, coccidiosis caused by Eimeria leads to severe enteric disease in captive musk deer, while little is known about these species, even for their classification. To the best of our knowledge, our work is the first comprehensive report on the coccidian species known from all musk deer. We summarized 10 species of Eimeria known to parasitize musk deer, including six new species: E. helini, E. huangi, E. oocylindrica, E. shengi, E. dolichocystis, E. kaii, Our research also demonstrated a high prevalence of infection in forest musk deer, usually with multiple Eimeria species. Thus, we argue that coccidia in the wildlife, especially for endangered animals in captivity, should be identified more deeply.

Acknowledgements. We are grateful to Prof. Xun Suo (China Agriculture University) for his valuable help in suggestions on the coccidia taxonomy, Ms. Yajun Fu (Beijing Forestry University) for her efforts in the field work. We also deeply thank the staff of the Breeding Centre of Forest Musk Deer in Pien Tze Huang (Fengxian, Shaanxi Province, Lixian, Sichuan Province), Hai Xing (Fengxian, Shaanxi Province), Da Ji Kang (Fengxian, Shaanxi Province), Feng Chun (Fengxian, Shaanxi Province), Jiu Yao (QingChuan, Sichuan Province), Chao Tian (QingChuan, Sichuan Province), especially Mr. Shike Chen, Mr. Baoqing Liu, Mr. Haibin Liu, Mr. Hongyong Wang, Mr. Changhong Li, Mr. Shumin Chen,
Mr. Qingjun Huang, Mr. Deyun Yang, Mr. Shiliang Feng, Ms. Xiaolan Wang, Mr. Benmo Jiang, Mr. Kun Li, Ms. Xiaoju Li, and Ms. Yanping Zhang for their kind help and support. This study was supported by the Fundamental Research Funds for the Central Universities (No. 2019YC01, No. 2019JQ0318, No. 2019ZY46).

\section{Conflict of interest}

No potential conflict of interest is reported by the authors.

\section{References}

1. Bezerra-Santos MA, Mendoza-Roldan JA, Thompson RA, Dantas-Torres F, Otranto D. 2021. Illegal wildlife trade: a gateway to zoonotic infectious diseases. Trends in Parasitology, 37(3), 181-184.

2. Cai YH, Lin H, Cheng JG, Wang Y, Fu WL, Zhu P, Wu J, Yang GY. 2016. Investigation on parasitic infection of captive forest musk deer in China. Sichuan Journal of Zoology, 35(01), 74-77.

3. Chen D, Cheng JG, Cai YH, Fu WL, Zhu P, Wang Y, Yan M, Yang GY. 2016. Prevalence of intestinal parasites in young captive Moschus berezovskii. Journal of Economic Animal, 20(4), 197-199.

4. Duszynski DW, Wilber PG. 1997. A guideline for the preparation of species descriptions in the Eimeriidae. Journal of parasitology, 333-336.

5. Frey JK, Yates TL, Duszynski DW, Gannon WL, Gardner SL. 1992. Designation and curatorial management of type host specimens (symbiotypes) for new parasite species. Journal of Parasitology, 930-932.

6. Green MJ. 1986. The distribution, status and conservation of the Himalayan musk deer Moschus chrysogaster. Biological Conservation, 35(4), 347-375.

7. Hu XL, Liu G, Wei YT, Wang YH, Zhang TX, Yang S, Hu DF, Liu SQ. 2018. Regional and seasonal effects on the gastrointestinal parasitism of captive forest musk deer. Acta Tropica, $177,1-8$

8. Hu XL, Wei YT, Huang SL, Liu G, Wang YH, Hu DF, Liu SQ. 2018. Effects of breeding center, age and parasite burden on fecal triiodothyronine levels in forest musk deer. PloS One, 13(10), e0205080.

9. Hua M, Yip H, Talbot P. 2013. Mining data on usage of electronic nicotine delivery systems (ENDS) from YouTube videos. Tobacco Control, 22(2), 103-106.

10. Levine ND. 1988. Progress in taxonomy of the Apicomplexan protozoa. Journal of Protozoology, 35(4), 518-520.

11. Levine ND, Ivens V. 1970. The coccidian parasites (Protozoa, Sporozoa) of ruminants. Urbana, llinois: University of Illinois Press, 183-185.

12. Levine ND, Ivens V. 1986. The coccidian parasites (Protozoa, Apicomplexa) of Artiodactyla. Urbana, llinois: University of Illinois, 1-265.

13. Li YM, Hu XL, Yang S, Zhou JT, Qi L, Sun XN, Fan MY, Xu SH, Cha MH, Zhang MS. 2018. Comparison between the fecal bacterial microbiota of healthy and diarrheic captive musk deer. Frontiers in Microbiology, 9, 300.

14. Liu ZB, Cheng JG, Dai XY. 2002. Regional distribution and countermeasures of coccidiosis in captive forest musk deer. China Herbivores, 03, 44

15. Matschoulsky S. 1947. Questions on the coccidia of wild mammals in Buraf-Mongolsko USSR. Trudy Buryet-Mongolskoi Zooveterinarnogo Instituta, Ulan-Ude, 3, 78-84. 
16. Meng XX, Zhou CQ, Hu JC, Li C, Meng ZB, Feng JC, Zhou YJ, Zhu YJ. 2006. Musk deer farming in China. Animal Science, 82(1), 1-6.

17. Pellérdy LP. 1974. Coccidia and coccidiosis. Akademiai Kiado: Berlin. p. 1-959.

18. Qiao Y, Zou F, Wei K, Yue B. 2007. A rapid sex-identification test for the forest musk deer (Moschus berezovskii) based on the ZFX/ZFY gene. Zoological Science, 24(5), 493-495.

19. Sha GR, Zhang HX, Cai YH, Wang HY, Liu HY. 1994. Two new species of Eimeria in domestic forest musk deer. Sichuan Journal of Zoology, 13(1), 1-4.

20. Sheng HL, Liu ZX. 2007. The musk deer in China. Shanghai Science and Technology Press: Shanghai. p. 1-249.

21. Singh B, Gautam KB, Sahoo S, Kumar A, Gupta SK. 2020. Complete mitogenome of Kashmir musk deer (Moschus cupreus) and its comparative phylogenetic relationships. Molecular Biology Reports, 47(12), 9757-9763.

22. Svanbaev SK. 1958. Coccidia of rodents of Central Kazakhstan. Trudy Instituta Zoologii: Akademii Nauk Kazahkskoi. p. 187-197.

23. Wang Y, Harris RB. 2015. Moschus berezovskii. The IUCN red list of threateded species, e.T13894A103431781. https://dx.doi. org/10.2305/IUCN.UK.2015-4.RLTS.T13894A61976926.en.

24. Wu JY, Wang W. 2006. The musk deer of china. China Forestry Publishing House: Beijing. p. 1-575.

25. Yang Q, Meng X, Xia L, Feng Z. 2003. Conservation status and causes of decline of musk deer (Moschus spp.) in China. Biological Conservation, 109(3), 333-342.

26. Zhou YJ, Meng XX, Feng JC, Yang QS, Feng ZJ, Xia L, Bartos L. 2004. Review of the distribution, status and conservation of musk deer in China. Folia Zoologica, 53(2), 129-140.

Cite this article as: Gao Y, Duszynski DW, Yuan F, Hu D \& Zhang D. 2021. Coccidian parasites in the endangered Forest Musk Deer (Moschus berezovskii) in China, with the description of six new species of Eimeria (Apicomplexa: Eimeriidae). Parasite 28, 70.

O PARASTE

An international open-access, peer-reviewed, online journal publishing high quality papers on all aspects of human and animal parasitology

Reviews, articles and short notes may be submitted. Fields include, but are not limited to: general, medical and veterinary parasitology; morphology, including ultrastructure; parasite systematics, including entomology, acarology, helminthology and protistology, and molecular analyses; molecular biology and biochemistry; immunology of parasitic diseases; host-parasite relationships; ecology and life history of parasites; epidemiology; therapeutics; new diagnostic tools.

All papers in Parasite are published in English. Manuscripts should have a broad interest and must not have been published or submitted elsewhere. No limit is imposed on the length of manuscripts.

Parasite (open-access) continues Parasite (print and online editions, 1994-2012) and Annales de Parasitologie Humaine et Comparée (1923-1993) and is the official journal of the Société Française de Parasitologie. 